\title{
Economic Progress in the Central Mississippi Valley
}

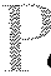
Valley ${ }^{x}$ states, though still below the national average, has advanced at a faster rate since 1950 than in the nation.

Many income-related factors have shown favorable trends in the region relative to the nation. These include employment in agriculture, proportion of the population living in urban areas, per cent of population employed, ratio of wages and salaries to personal income, proportion of employment in professional and technical occupations, and transfer payments. With respect to median years of schooling, the region's rate of gain has not been so great as the national average.

Per capita personal income in the Central Mississippi Valley in 1966 was $\$ 2,296$, well below the $\$ 2,940$ national average. Per capita income within the region ranged from $\$ 1,751$ in Mississippi to $\$ 2,845$ in Missouri. With the exception of Missouri, the states of the region were in the lowest fifth when all states in the nation were ranked according to income.

Personal income data provide some indication of economic welfare and progress. They show the relative amount of funds available for personal spending. They do not, however, take into account differences in living costs between areas and occupations. This article examines factors which are associated with personal income levels and relates those factors to conditions in the Central Mississippi Valley states.

Market forces have had a favorable impact on per capita incomes in the Central Mississippi Valley states in the past 16 years. From place to place and from occupation to occupation, movements of labor and the creation of jobs have resulted from the forces of the market. The incentive for higher wages has motivated

\footnotetext{
1 The Central Mississippi Valley, as used in this article, consists of the states of Arkansas, Kentucky, Mississippi, Missouri, and Tennessee.

2See "Why Kentucky Ranks Low Among the States in Per Capita Personal Income" Research Briefs, Bureat of Business Research, University of Kentucky, November 1966.
}

workers to move from low-income to high-income geographic areas and occupations. The migration of regional labor to higher paying jobs outside the area is indicated by the disparity in rates of growth between the regional and national population. Similarly, availability of labor has offered incentive for firms to locate in the Central Mississippi Valley. As new jobs have been created and the demand for labor has increased, the impact has been noted in such income-related factors as proportion of population employed, the proportion employed in agriculture, and the ratio of urban to total population.

Population trends in the region, coupled with the birth rate data, indicate that the labor force has responded to employment opportunities and generally higher wage rates elsewhere. Emigration has apparently been sizable since 1950 . Population in the region rose only 0.7 per cent per year from 1950 to 1966 , compared with a 1.6 per cent rate in the nation. The disparity in the regional and national population growth rates, however, has been declining in recent years. From 1950 to 1960 population in the five Valley states increased at only about one-third the national rate of growth, while from 1960 to 1966 the regional rate of gain was about two-thirds of the national rate. A very rapid movement of population out of agriculture was probably a major factor in the low regional rate of population gain during the decade from 1950 to 1960. Agricultural employment in the Valley declined at an average annual rate of 7 per cent, compared with a national rate of 3 per cent.

The birth rate in the region probably exceeded the national rate in most years from 1950 to 1966. In 1950 the number of births per thousand exceeded the 24.1 national rate in four of the five Valley states. In 1960 the birth rate was higher in two of the Valley states than in the nation, while in each of the years 1964 and 1965 the birth rate was higher in three of the Valley states than in the nation. Therefore, the lower rate of population growth in the states of the region seems to be due to emigration. 


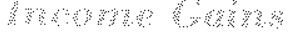

Since 1950 per capita income has grown faster in the Central Mississippi Valley than in the nation. In the region it grew at an annual rate of 5 per cent, while in the nation it grew at a rate of only 4.3 per cent. In 1966 per capita income in the Valley was 78 per cent of the national average, up from 74 per cent in 1960 and from 71 per cent in 1950 .

The income gap between region and nation is narrowing in each state. The greatest relative gains have been in the southern part of the region where the lowest relative incomes have prevailed. From 1950 to 1966 average income rose from 55 to 69 per cent of the national level in Arkansas and from 50 to 60 per cent in Mississippi. Per capita income increased in Arkansas at a 5.7 per cent annual rate and in Mississippi at a 5.4 per cent rate. Per capita income in Kentucky and Tennessee rose at a 5.2 per cent average rate and in Missouri at a 4.4 per cent rate, slightly above the 4.3 per cent national rate.

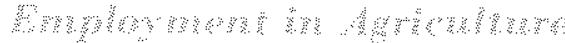

The proportion of workers employed in agriculture in the region has remained high relative to the national average. In 1966, 10 per cent of total employment in the region was in agriculture, compared with 5.5 per cent in the nation. Mississippi and Kentucky had 16 and 12 per cent of the employed labor force in agriculture, respectively, while Arkansas, Missouri, and Tennessee each had more than 8 per cent so employed. Agriculture generally accounts for a larger proportion of total income in areas where per capita income is small than in areas where per capita income is large. In the Central Mississippi Valley more than 6 per cent of income was derived from agriculture in 1965 , compared with 3 per cent in the nation.

Although still relatively high, employment in agriculture in the region has declined sharply since 1950. Arkansas and Mississippi, the states which have shown the most rapid gains in per capita income, have had the most rapid declines in agricultural employment. The movement out of agriculture was most pronounced in Arkansas, with employment in the farm sector declining from 1950 to 1966 at an 8.3 per cent annual rate. Agricultural employment in Mississippi declined at the rate of 5.3 per cent during the period, while the regional and national rates of decline were 4.5 and 3.9 per cent, respectively.

The shift of workers out of agriculture has resulted from rapid technical change in that industry. The shift to more productive resource combinations in farming has been phenomenal. One vital aspect of the recom- bination has been more land and capital per worker, which was made possible by extensive use of modern machinery. Changes in many farm production techniques have favorably infuenced farm production efficiency. The number of commodities produced per farm has declined. Each farmer has become a specialist in the mass production of one or a few products. These changes have led to a remarkable increase in farm output per worker and a decline in the number of workers necessary for food and fiber production.

This increased farm productivity has been of benefit to the region and the nation. Output of food and fiber products has increased, providing consumers with an abundant supply at lower costs. Increased efficiency has released workers from agriculture to produce nonfarm products and services on which consumers presently prefer to spend a larger portion of their incomes. At the same time, income per farmer has increased rapidly. ${ }^{3}$

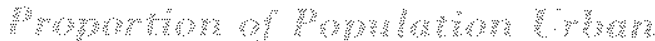

Since the economy of the Central Mississippi Valley is still heavily agricultural, the ratio of urban to total population has remained relatively low. The region as a whole is well below the national average in per cent of population living in urban areas. Within the region, the proportion of population living in urban areas in 1966 ranged from 40 per cent in Mississippi to 69 per cent in Missouri, compared with about 70 per cent in the United States. In most states of the region urbanization corresponded closely with the per capita income level. The only state of the region in which urban population and per capita income were not closely associated was Kentucky which was substantially lower in urban population, but only 25 per cent below the national average in per capita income. ${ }^{4}$ Relatively high earnings of production workers in manufacturing partially offset the negative influence of a large rural population in this state.

As a result of the rapid movement out of agriculture, urbanization has proceeded much faster in the region than in the nation. Urbanization in the region rose to 77 per cent of the national proportion in 1966 , up from 60 per cent in 1950 . Although major urbanization gains occurred throughout the area, the change was greatest in Tennessee, which rose from 47 to 77 per cent of the national proportion during the period.

"See "Farm Income and Price Trends" in the August 1967 issue of this Review.

4 Computed as an index number using the United States figure for the comparable year as the base equaling 100 . 
Toble I

PERSONAL INCOME AND ASSOCIATED FACTORS IN THE CENTRAL MISSISSIPPI VALLEY

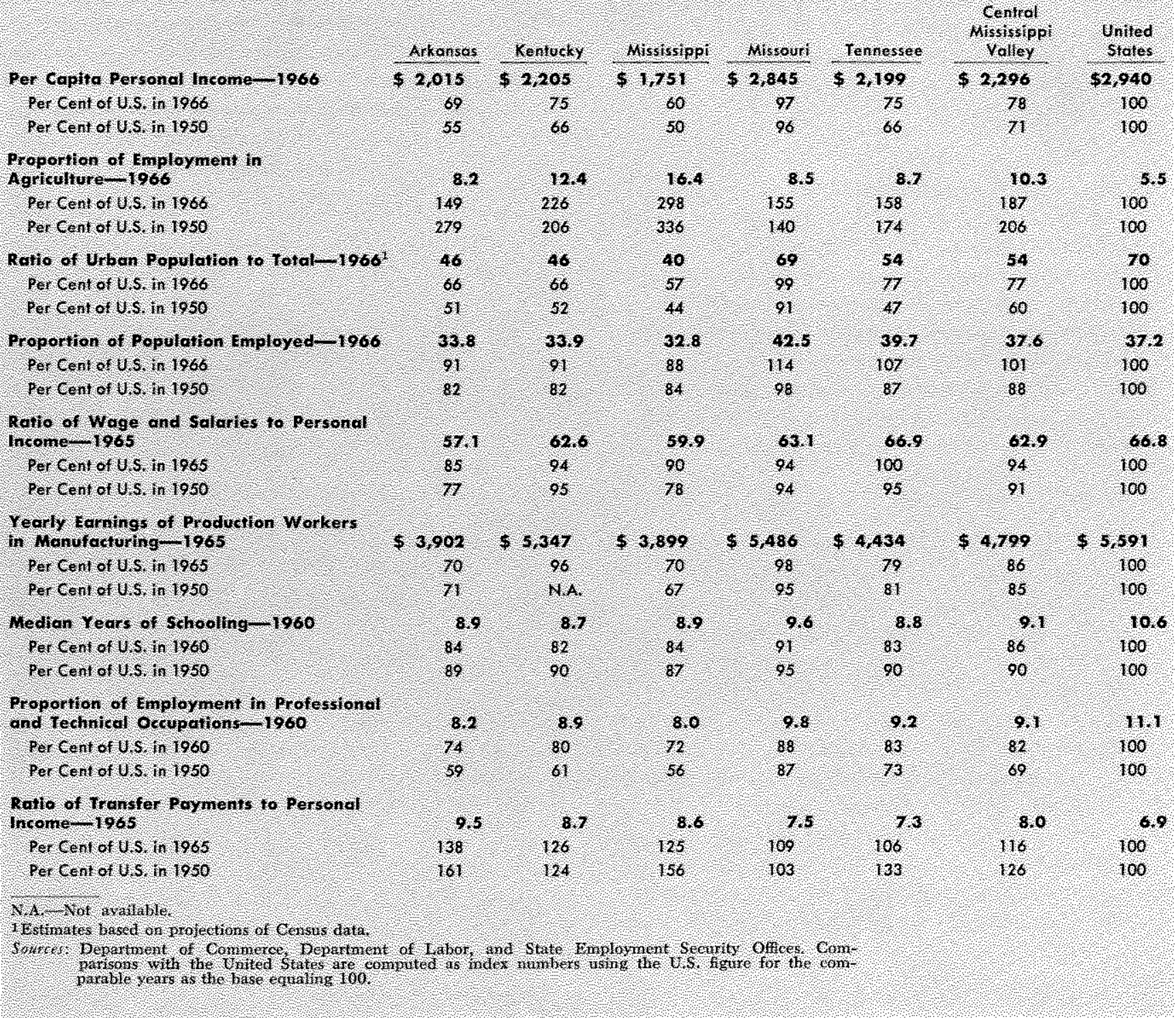

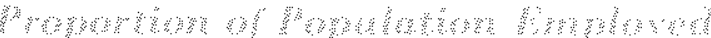

With the decline in agricultural employment and the rapid increase in urbanization in the region, the proportion of the population employed had moved ahead of the national proportion by 1966 . In the Valley states 38 per cent of the population was employed in 1966 compared with 37 per cent in the nation. Opportunities for employment by women greatly increase as families move from rural to urban areas. Furthermore, the movement of industry into many rural communities of the region has enhanced nonfarm employment of people living on farms.

In 1966 both Missouri and Tennessee were well above the national average in proportion of population employed. Mississippi, which has greater dependence on agriculture, had the lowest proportion with only 33 per cent of its population employed. Nevertheless, its proportion was still 88 per cent of the national average.

Nonagricultural employment gains in all states of the region except Missouri exceeded the national average from 1950 to 1966. Mississippi led the group with a 3.2 per cent rate of increase, while the 1.7 per cent rate in Missouri was only slightly below the national average of 1.9 per cent. The gain in the region was at an average rate of 2.4 per cent. 


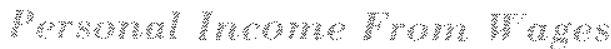

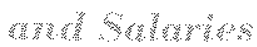

A relative gain in proportion of personal income from wages and salaries has been associated with the increase in the proportion of the population employed in nonfarm pursuits in the region. Predominantly agricultural areas generally have a smaller number of wage and salary employees and derive a smaller per cent of income from such employment.

In the region the proportion of personal income derived from wages and salaries rose from 91 per cent of the national average in 1950 to 94 per cent in 1965. Greatest relative gains were in Arkansas and Mississippi where employment in agriculture declined most rapidly. In Arkansas the proportion rose from 77 to 85 per cent of the national average during the period, while in Mississippi the proportion rose from 78 to 90 per cent. In Kentucky, Tennessee, and Missouri, where agricultural employment declined less rapidly, the gains in proportion of income from wages and salaries were smaller. Kentucky and Missouri made no gain relative to the national average. Tennessee moved up only five percentage points from 1950 to 1965 , but did reach the national average in proportion of income from this source in 1965 .

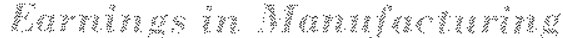

Annual earnings of production workers in manufacturing in the Central Mississippi Valley were about 14 per cent below the national level in 1965. Earnings of production workers nationally averaged $\$ 5,591$. In the region, average earnings were $\$ 4,799$, ranging from $\$ 3,899$ in Mississippi to $\$ 5,486$ in Missouri. Such earnings in Arkansas and Mississippi were 30 per cent less than the national average and 21 per cent below the national level in Tennessee. In both Kentucky and Missouri, earnings were about the same as in the nation.

Yearly earnings of production workers in manufacturing in a given state are related both to general wage levels in the area and the industry mix. In the region as a whole low-wage industries prevail as would be expected in any region in the relatively early stages of industrialization. The proportion of income derived from high-wage durable goods industries was 24 per cent below the national average with each state below the national figure.

Employment data for the Central Mississippi Valley substantiate the relatively unfavorable industry mix observed by analyzing income data. The four states of Arkansas, Kentucky, Mississippi, and Tennessee had only 47 per cent of their manufacturing employment concentrated in the higher wage durable goods in dustries, compared with 59 per cent in the nation. In these four states 14 per cent of manufacturing employment was in lumber and furniture, which are the two durable goods industries with lowest wages nationally. Only 6 per cent of the manufacturing employment in the nation was in those two categories. The four states had only 7.5 per cent of manufacturing employment in the highest-wage industries of transportation and primary metals, while nationally 17 per cent of the workers were employed in those two categories.

Arkansas, Kentucky, Mississippi, and Tennessee had a high concentration of workers in the low-wage nondurables. About 15 per cent of the manufacturing employees in the four states worked in the lowest-wage apparel industry, compared with 7 per cent in the nation. Nationally, the average weekly wage in the apparel industry in 1966 was only 62 per cent of the average wage for all manufacturing. The fact that nearly one-fourth of the manufacturing workers in Mississippi were employed in the apparel industry in 1966 helps to explain the low per capita income in that state.

Although Missouri had a somewhat heavier concentration of employment in nondurables than the nation, the industry mix was much more favorable than in the other Central Mississippi Valley states. Missouri also had a much higher per capita income than the other four regional states. More than 17 per cent of Missouri's manufacturing workers were employed in the high-wage transportation equipment industry, compared with 10 per cent in the nation and only 4 per cent in the other Valley states.

The fact that a large proportion of workers are employed in the lower-wage nondurable industries in most of the Valley states indicates that much of the region is in a transition stage. It is moving from a predominantly agricultural economy to a more balanced industrial economy, Many employees in the lower-wage industries were formerly under-employed farm workers. Employment in nondurable industries has thus served to raise the income level of these workers and of the region. Furthermore, if these industries had not provided employment in the region. greater migration to other areas would have occurred. The expense of these population movements must be equated with the potential gain.

Since 1950 the region has about kept pace with the nation in average earnings of production workers in manufacturing. Mississippi and Missouri made small relative gains which were almost offset by relative losses in the remaining states. 
The failure of the region to grow faster than the nation in production worker earnings is probably related to both supply and demand conditions in the labor market and to the level of training achieved by labor in the area.

In 1950 the labor supply in the region was apparently excessive in relation to job opportunities. Most of the excess, however, was in the agricultural sector in the form of under-employed workers, i.e., workers that could be eliminated from the farm work force without any reduction in output or net income within the industry. There was a mass exodus of these workers from agriculture into other occupations both within and out. side the region. This stream of labor flowing into the nonfarm sector was a factor in the downward pressure on wages. Wage rates in the area thus failed to gain relative to the national average despite a major increase in the number of jobs and demand for labor.

This type of labor flowing into the nonfarm sector was not welltrained. Industries locating in areas where large numbers of such workers could be recruited were of the type that could utilize relatively low-skilled workers. Such industries also pay relatively low wages. The buildup of such industries in the region was thus a major factor in both the rapid growth in nonfarm employment and only average growth in wages of production workers in manufacturing. Otherwise, with the relatively low wage rates in the region one would have expected the gap between regional and national wage rates of manufacturing workers to have closed.

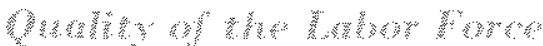

Perhaps the most important factor in income determination is the quality of the labor force. Two measures of quality included in this article are median years of schooling of the adult population and proportion of population employed in professional and

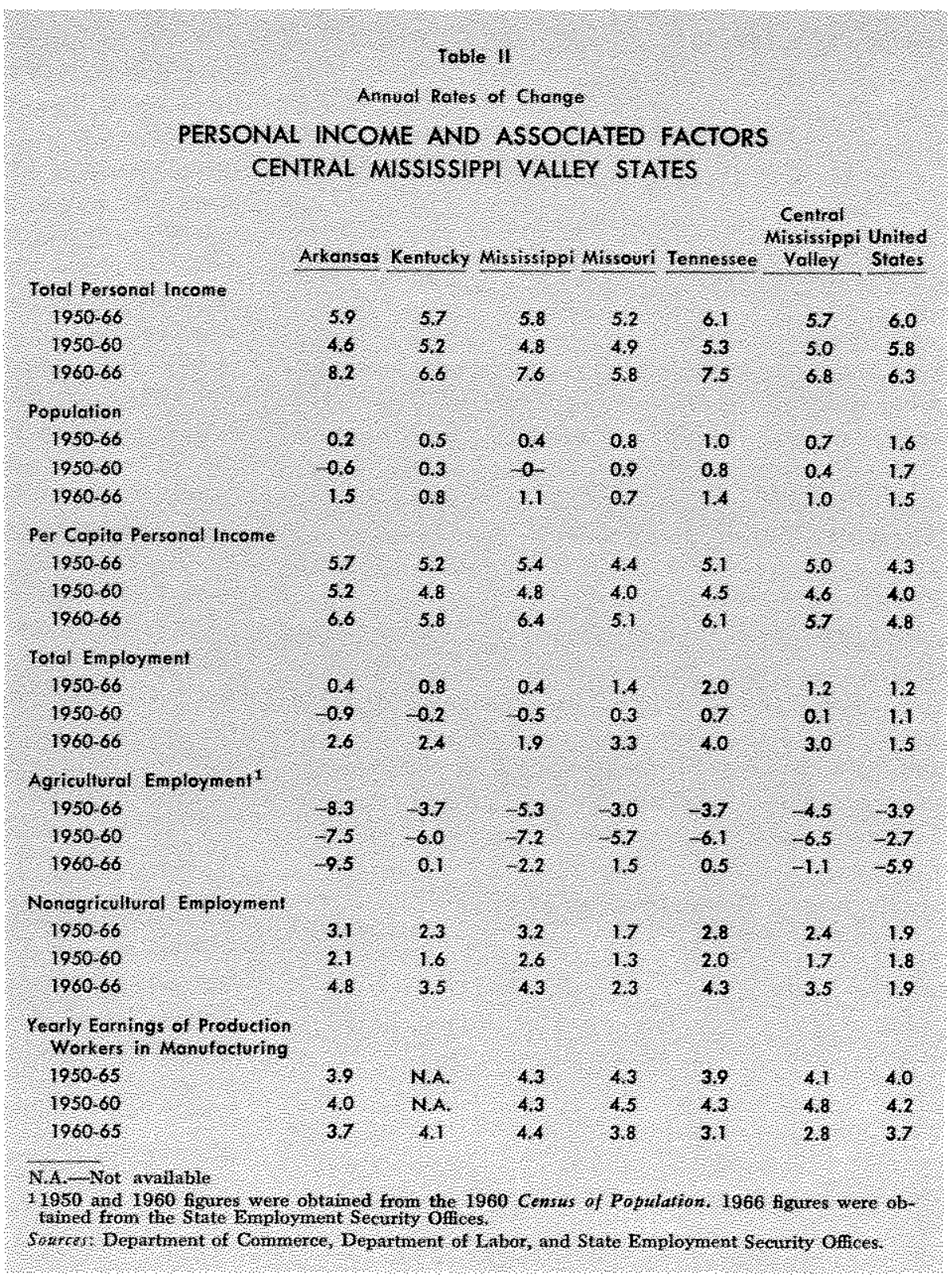

technical occupations. A high rating in these factors is generally associated with high-quality labor and high labor returns. All states of the region ranked well below the nation in both factors in 1960 , the latest year for which data are available. On the basis of median years of schooling completed by the adult population in 1960 , the region was 14 per cent below the national average. The median education of the adult population of Missouri, the highest in the area, was 9.6 years, a year below the national level. Median years of schooling in the other four states ranged from 8.7 in Kentucky to 8.9 years in Arkansas and Mississippi.

Measured on the basis of employment in the more highly-trained professional and technical occupations, 
the labor force in the Central Mississippi Valley states is relatively unskilled. The region was well below the national average in proportion of employment in professional and technical occupations in 1960, with Mississippi and Arkansas having the smallest percentage of workers in those occupations. Missouri and Tennessee ranked highest in proportion of professional and technical workers, but both states were well below the national average.

Measures of quality of the labor force in the Central Mississippi Valley show mixed trends relative to the nation during the decade from 1950 to 1960 . The median years of schooling in the region declined from 90 to 86 per cent of the national median. Each state lost ground compared to the national level. However, the proportion of employment in professional and technical occupations increased faster in all five states than in the nation. Gains were greatest in Arkansas and Mississippi, the states which ranked lowest in this factor at the earlier date. This high rate of gain probably reflects the sizable movement of population out of agriculture in these states, where a number of these people had received their education. Conversely, Missouri, which ranked highest in professional and technical employment, had the lowest rate of gain.

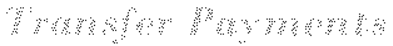

Transfer payments, like agricultural employment, relate inversely to income. They tend to be high in low-income areas as many are designed to aid persons with low incomes. The Central Mississippi Valley was 16 per cent above the nation in proportion of income derived from transfer payments in 1965. Arkansas, Kentucky, and Mississippi were particularly high in this factor, while Missouri and Tennessee were only slightly above the national average. Although transfer payments relate inversely as an indicator of income, they also have an equalizing effect on income. They are financed primarily by income and social security taxes, and relatively small amounts are collected per capita in states with low per capita incomes. Thus Government welfare programs have tended to enhance per capita income in the relatively low income states of the Central Mississippi Valley.

Transfer payments as a per cent of personal income in the region declined sharply relative to the nation from 1950 to 1960 and remained constant from 1960 to 1965. The declines were substantial in Arkansas, Mississippi, and Tennessee for the entire period from 1950 to 1965. In contrast, Kentucky and Missouri showed small increases relative to the national proportion.
Whanders

In summary, market forces are tending to reduce the income gap between the region and the nation. The rate of growth in per capita income in each of the five states has been greater than the national average since 1950. Most factors generally associated with per capita income levels have shown larger gains in the region than in the nation. The region has improved in proportion of employment in agriculture, urbanization, proportion of population employed, ratio of wages and salaries to personal income, proportion of employment in technical and professional occupations, and ratio of transfer payments to personal income. The region has kept pace with the nation with respect to yearly earnings of production workers in manufacturing. The failure of earnings of production workers to make greater gains than the nation, despite the rapid growth of nonfarm jobs, may indicate that there is an abundant supply of labor in the area in relation to job opportunities. A large reservoir of under-employed and low-wage labor existed in the region, particularly on farms, which tended to reduce the upward pressure on wages and salaries as new jobs were created. Once this reservoir of labor is depleted, upward pressure on wage rates will likely increase.

In median years of schooling, the region lags the nation substantially, and the gap widened during the decade ending in 1960. In this important factor, each of the Central Mississippi Valley states may be overlooking its greatest opportunity for increasing personal income and improving welfare. Professor T. W. Schultz of the University of Chicago, one of the nation's outstanding economists, reports:

Two lessons may be drawn from studies that have been made of schooling as a source of economic growth. During the last three decades, schooling has been a larger source of growth than material capital represented by structures, equipment, and inventories as presently measured. The other lesson pertains to earlier decades and to the decades ahead. Between 1909 and $1929, \ldots$ schooling play. ed a much smaller role in growth than it has since then. During the next two decades the prospects are that schooling will continue to be a major source of growth. ${ }^{5}$

${ }^{5}$ Theodore W. Schultz, The Economic Value of Education, New York: Columbia University Press, 1963, p. 44.

Clifton B. Luttrell. Clatre Armentrout 